\title{
CrimRxiv
}

\section{Personality pathways to aggression: Testing a trait- state model using immersive technology}

Jean-Louis van Gelder, Reinout E. de Vries, Iris van Sintemaartensdijk, Tara Donker

Published on: Mar 07, 2022

DOI: $10.21428 / \mathrm{cb} 6 \mathrm{ab} 371.8 \mathrm{c} 8 \mathrm{e} 3 \mathrm{fc} 5$

License: Creative Commons Attribution 4.0 International License (CC-BY 4.0). 
